\title{
Hábitos de estudo e estilos parentais: estudo correlacional
}

\author{
Patrícia Nunes da Fonsêca \\ Universidade Federal da Paraíba - PB \\ Patrícia Oliveira de Andrade \\ Universidade Federal da Paraíba - PB \\ Jérssia Laís Fonsêca dos Santos \\ Universidade Federal da Paraíba - PB \\ Jéssica Emmily Monteiro Cunha \\ Universidade Federal da Paraíba - PB \\ Juliana Henrique de Assis Albuquerque \\ Universidade Federal da Paraíba - PB
}

\begin{abstract}
Resumo
O presente estudo teve por objetivo correlacionar as dimensões dos estilos parentais (responsividade e exigência) com os hábitos de estudo. Participaram deste estudo 600 estudantes, com idades entre 11 e 20 anos ( $m=14,3 ; d p=2,32$ ), pertencentes, em sua maioria ( $57,5 \%)$, ao sexo feminino. Esses estudantes eram alunos de escolas públicas e particulares do município de João Pessoa (PB). Os dados foram analisados no programa estatístico PAWS (versão 20), onde se calculou o coeficiente de correlação e a MANOVA. Os resultados mostraram que os hábitos de estudo se correlacionaram com a dimensão responsividade materna $(r=0,19 ; p<0,01)$ e paterna $(r=0,16 ; p<0,01)$, e que as variáveis sociodemográficas (sexo, escolaridade e escola) influenciaram os hábitos de estudo e as dimensões dos estilos parentais. Concluiu-se que os pais que demonstram responsividade alta influenciam de forma positiva a construção de hábitos de estudos, embora haja necessidade de mais estudos.
\end{abstract}

Palavras-chave: Inventário de estilos parentais; hábitos de estudo; adolescentes.

\section{Study habits and parenting styles: correlational study}

\begin{abstract}
In this study we aim at correlating the dimensions of parenting style (demandingness and responsiveness) with study habits. The research included 600 students aged between 11 and 20 years (mean $=14.3, S D=2.32$ ), belonging mostly $(57.5 \%)$ to female students in public and private schools in the city of João Pessoa (PB). We analysed the data through PAWS (version 20) statistical program and calculated the correlation coefficient and MANOVA. The results show that the study habits correlated with maternal responsiveness dimension $(r=0.19, p<0.01)$ and paternal $(r=0.16, p$ $<.01)$ and sociodemographic variables (sex, schooling and school) influenced the study habits and dimensions of parenting styles. We conclude that parents who demonstrate high responsiveness influence positively on the building habits of study, although there is a need for further studies. Keywords: Parenting Style Inventory; study habits; adolescents.
\end{abstract}

\section{Hábitos de estudio y estilos parentales: estudio correlacional}

\section{Resumen}

El presente estudio tuvo el objetivo de conocer en qué medida los estilos parentales (autoritativo, autoritario, negligente y permisivo) se correlacionan con los hábitos de estudio. Participaron de este estudio 600 estudiantes con edades entre 11 y 20 años (promedio= 14,3; $S D=2$ ), pertenecientes em sua mayoría $(57,5 \%)$ al sexo femenino, y procedentes, equitativamente, de escuelas públicas y privadas del municipio de João Pessoa (Estado de Paraíba). Los resultados mostraron que los hábitos de estudio se correlacionaron de forma significativa con todos los estilos parentales, sin embargo el estilo parental permisivo presentó mayor correlación $(r=0,14 ; p<0,01)$. Se concluye que el estilo parental adoptado por los padres en la relación con los hijos influye en la construcción de hábitos de estudios, especialmente cuando los padres demuestran una mayor capacidad de respuesta y tratan la cuestión de la autoridad de forma objetiva, con actitudes que promuevan el desarrollo de la autoestima y de la autonomía de los hijos.

Palabras Clave: inventario de los estilos parentales; hábitos de estudio; adolescentes. 


\section{Introdução}

Ao longo dos últimos anos, inúmeros estudos têm procurado compreender o impacto que os pais exercem no desenvolvimento sociocognitivo dos filhos. As pesquisas mostram que os estilos parentais estão relacionados a diversos aspectos do desenvolvimento psicossocial de crianças e adolescentes, como, por exemplo, autoestima, ajustamento social, psicopatologia e desempenho escolar (Camacho, \& Matos, 2007; Cia, Pereira, Del Prette, \& Del Prette, 2006; Justo, \& Lipp, 2010; Rinhel-Silva, Constantino, \& Rondini, 2012; Weber, Brandenburg, \& Viezzer, 2003).

Segundo Reppold, Pacheco, Bardagi e Hutz, (2002), os estilos parentais correspondem a um conjunto de atitudes e manifestações dos pais em relação aos filhos relacionadas às questões de poder, hierarquia, apoio emocional e estímulo à autonomia, criando um clima psicológico-emocional. Com essas atitudes os pais estimulam nos filhos a disciplina, a independência, a autonomia e a responsabilidade, ao mesmo tempo em que modelam os comportamentos considerados adequados socialmente.

Maccoby e Martin (1983) classificaram os estilos parentais em quatro tipos: autoritário, autoritativo, permissivo e negligente - os quais resultam da combinação de duas dimensões denominadas exigência e responsividade. A exigência refere-se a quanto os pais estão disponíveis para proceder como agentes socializadores de seus filhos, supervisionando e monitorando seu comportamento, estabelecendo expectativas de desempenho e exercendo disciplina de modo consistente. As características da responsividade incluem as atitudes compreensivas dos pais para com os fiIhos que visam promover o desenvolvimento da autoafirmação dos jovens, principalmente por meio do apoio emocional, da comunicação recíproca e do estímulo à autonomia. Deste modo, o estilo parental autoritário caracteriza-se por alta exigência e baixa responsividade; o autoritativo, por alta exigência e responsividade; o permissivo, por baixa exigência e alta responsividade; e o estilo negligente, por baixa exigência e responsividade.

Os pais autoritários costumam usar o poder para exigir dos filhos certos comportamentos, sendo pouco atentos e sensíveis às necessidades deles. Esses pais não dão explicações a seus filhos, principalmente quando Ihes dão ordens; não estimulam as respostas verbais, nem costumam aceitar os argumentos dos filhos (Weber, Selig, Bernardi, \& Salvador, 2006). Eles impõem muitas regras e limites, dão pouco afeto e não se envolvem com os filhos; controlam e mantêm regras porque acreditam que as crianças têm que obedecer a elas; punem quando os filhos são indisciplinados e por eles tomam decisões. Por outro lado, os pais que adotam o estilo parental autoritativo são aqueles que se comunicam bem com os filhos e estão dispostos a aceitar seus argumentos. Praticando o diálogo, orientam e controlam o comportamento dos filhos, valorizando as decisões autônomas e os comportamentos disciplinados; respeitam os interesses e os direitos dos filhos; exercem firme controle nos pontos de divergência, no exercício do pátrio poder, mas sem intimidar os filhos (Granetto, 2008).

Semelhantemente aos pais do estilo autoritativo, os permissivos também se comunicam bem com os filhos e utilizam o diálogo para conseguir inibir comportamentos indesejáveis, porém exigem pouco, não controlam os filhos nem Ihes permitem regular suas próprias atividades, levando-os a raciocinar sobre suas ações. Os pais permissivos acreditam que os filhos devem expressar seus sentimentos e impulsos para se desenvolverem naturalmente, por isso não Ihes impõem regras nem limites e acabam cedendo facilmente aos seus pedidos (Granetto, 2008). Em relação aos pais do estilo negligente, Justo e Lipp (2010) afirmam que esses demonstram pouco afeto e nada exigem dos filhos, aparentando indiferença; permitem que se cuidem e se responsabilizem por si próprios. São pais que passam pouco tempo com os filhos e apenas atendem às suas necessidades básicas; não os ajudam nos seus trabalhos escolares e não se preocupam com sua socialização.

Segundo Salvo (2010), os estilos parentais podem se constituir tanto em fator de risco quanto em fator de proteção de condutas socialmente desviantes, o que indica que, se por um lado a adversidade e negligência parentais contribuem para o desenvolvimento de indivíduos com distúrbios de conduta, por outro lado, práticas corretas, associadas a um bom funcionamento familiar, à criação de um vínculo afetivo, a apoio e vigilância parentais são indicativos de fatores protetores que reduzem a probabilidade de crianças e/ou adolescentes adotarem comportamentos desviantes. Neste sentido, estudos revelam que os filhos de pais negligentes geralmente são inseguros, impulsivos, antissociais e muito menos orientados para a realização escolar. Crianças e adolescentes criados nesse tipo de família têm piores performances em todas as áreas e podem ter desenvolvimento atrasado, além de problemas afetivos e comportamentais. Em contrapartida, os filhos de pais autoritativos costumam apresentar autoestima mais elevada, são mais independentes e demonstram autoconfiança, obtendo melhores notas na escola e sendo classificados como competentes em diversas áreas (Pacheco, Silveira, \& Schneider, 2008; Rinhel-Silva e cols., 2012; Weber e cols., 2006).

Pacheco, Teixeira e Gomes (1999), ao analisarem a relação entre os estilos parentais, o ajustamento escolar e o desenvolvimento acadêmico dos jovens, observaram que os filhos de pais negligentes apresentavam maiores níveis de comportamento agressivo e de insatisfação com o próprio comportamento, ao contrário do que ocorria com os filhos dos pais autoritativos, que apresentavam melhores desempenhos escolares e maior confiança em suas próprias habilidades. Também observaram que os jovens filhos de pais autoritários se mostraram significativamente mais ansiosos que os filhos de pais permissivos e negligentes. Os resultados sugerem que a dimensão exigência esteja associada a indivíduos preocupados e inseguros quanto aos seus próprios desempenhos, mesmo apresentando um repertório adequado (Camacho, \& Matos, 2007; Pacheco e cols., 1999; Salvo, 2010). 
Lozano, Mascarenhas e Blanco (2004) comprovaram que a pressão moderada dos pais sobre o comportamento dos filhos pode resultar em um efeito positivo na motivação e no desempenho escolar, porque, do ponto de vista dos filhos, os pais estariam com a atenção voltada para eles, fato que possibilita a construção de uma autoimagem positiva acerca deles mesmos. Nesta perspectiva, Santos e Graminha (2006), em seu estudo com crianças entre seis e dez anos de idade, verificaram que o grupo de crianças que apresentou melhor desempenho escolar era proveniente de famílias nas quais os pais se envolviam nas atividades acadêmicas de seus filhos, participando e organizando-as de modo a criar uma rotina diária de estudo, o que sugere que o envolvimento parental seja um fator de proteção para as crianças em idade escolar. Diante do exposto, pode-se supor que os estilos parentais podem influenciar a construção de hábitos de estudo, comportamento importante para uma boa aprendizagem.

Segundo Carita, Silva, Monteiro e Diniz (1997), o hábito de estudo é definido como uma estratégia de diversificação de apoio aos alunos que visa à aquisição e/ ou desenvolvimento de um conjunto de competências básicas que influenciam positivamente o rendimento escolar. Envolve inúmeros comportamentos, como, por exemplo, organizar e folhear o material escolar, fazer a lição, ler um texto e responder perguntas. É uma ferramenta útil para o estabelecimento de objetivos, o planejamento de atividades e a distribuição do tempo (Regra, 2004).

Watkins e Coffey (2004) descrevem o hábito de estudo como uma habilidade que o aluno desenvolve de forma consciente para alcançar a realização de atividades de forma concentrada e persistente. É um processo contínuo que visa adquirir componentes necessários à prática do estudo, como motivação para estudar e estratégia de aprendizagem.

A motivação diz respeito aos aspectos subjetivos que direcionam o comportamento para um determinado fim (Maximiano, 2008). Segundo Carita e colaboradores (1997), o aluno motivado tem maior nível de concentração e persistência nas tarefas escolares, o que lhe permite obter satisfação quando atinge os objetivos estabelecidos. De modo semelhante à motivação, as estratégias de aprendizagem utilizadas durante o estudo também são relevantes para o desenvolvimento dos hábitos, pois o aluno que tem a capacidade de pensar sobre seu próprio processo de aprender é capaz de selecionar a atividade mais adequada para ser executada durante seus estudos. Sobre isto, Boruchovich (1999) afirma que as estratégias de aprendizagem expressam comportamentos dos alunos sobre a construção do conhecimento, portanto estão intrinsecamente relacionadas com os hábitos de estudo. Além destes dois componentes, ressalta-se ainda a organização temporal dos momentos de estudo, já que a definição prévia de horários ajuda na autonomia do estudante e na economicidade de energia durante o processo de aprendizagem, evitando preocupação, estresse e ansiedade nos dias que antecedem a avaliação (Rosário e cols., 2010).
Para ser bem-sucedida, a aprendizagem requer boa organização e planejamento do estudo, pois, à medida que o aluno aprende a estudar, melhora o seu desempenho na escola e nas avaliações, o que aumenta a autoestima e segurança (Watkins, \& Coffey, 2004); todavia, no cenário nacional tem-se percebido que os alunos não apresentam hábitos de estudo definidos, aspecto que tem contribuído para o baixo índice de desempenho acadêmico observado entre os estudantes do Ensino Fundamental e Ensino Médio, conforme mostra o Instituto Nacional de Estudos e Pesquisas Educacionais Anísio Teixeira - Inep (2011).

A falta de estímulo para a criação de hábitos de estudo durante o Ensino Fundamental e o Ensino Médio vem se reproduzindo no Ensino Superior. Watanabe, Cassetari, Santos, Lombard-Platet e Di Domenico (2001), pesquisando estudantes de Psicologia de $1^{\circ}$ e $5^{\circ}$ anos, observaram que a população investigada não possuía hábitos de estudo eficientes. A maior dificuldade apresentada era manter a atenção concentrada nas explicações, o que compromete a compreensão do conteúdo da aula. Também verificaram percentuais de insuficiência quanto às categorias método de estudo e apontamentos. Diante de tais resultados, os autores mostraram a necessidade de ações preventivas no que se refere à elaboração de intervenções psicopedagógicas que contribuam para a adoção de uma metodologia de estudo eficiente, focada em hábitos de estudo.

Benson, Buckley e Medrich (1980), pontuam que o uso do tempo é um aspecto importante para um bom rendimento escolar. Os autores afirmam que quando os pais estimulam a independência dos filhos, elogiam sua produtividade e o cumprimento das atividades e metas estabelecidas, estão ensinando-os a usar o tempo com sabedoria. Como se vê, a participação dos pais no processo de formação de hábitos e de fiscalização das atividades acadêmicas em casa pode ser fundamental para o bom desempenho acadêmico.

Ao se delimitar o problema proposto, teve-se como objetivo do estudo correlacionar as dimensões dos estilos parentais (responsividade e exigência) com os hábitos de estudo dos adolescentes paraibanos. Especificamente, pretendeu-se verificar a interferência das variáveis sociodemográficas (sexo, escolaridade e tipo de escola) nos hábitos de estudo e nas dimensões dos estilos parentais (responsividade e exigência). Os procedimentos da pesquisa e os resultados alcançados estão descritos a seguir.

\section{Método}

\section{Amostra}

Participaram 600 estudantes $(57,5 \%$ mulheres e $42,5 \%$ homens), com idades entre 11 e 20 anos $(m=14,3$; $d p=2,32)$, cursando o sétimo $(33,4 \%)$ e o nono $(33,3 \%)$ ano do Ensino Fundamental e o segundo ano (33,3\%) do Ensino Médio Os participantes estão distribuídos equitativamente entre instituições de ensino das redes pública e privada 
do município de João Pessoa (PB). A amostra foi de conveniência (não probabilística), tendo participado os jovens que, autorizados pela direção de cada escola e pelos pais, concordaram em responder voluntariamente o questionário.

\section{Instrumentos}

Os participantes foram solicitados a responder um livreto contendo duas escalas e um conjunto de informações sociodemográficas: a Escala de Hábitos de Estudo e o Quiasriona'rio de Percepção dos Pais.

A Escala de Hábitos de Estudo (EHE) foi originalmente construída em inglês por Hodapp e Henneberger (1983) e é composta de oito itens, os quais avaliam a percepção dos alunos acerca de seus hábitos de estudar (e.g., Item 1- Algumas vezes fico escutando música, assistindo televisão ou lendo quando deveria estar estudando; Item 2- Muitas vezes me sinto distraído quando quero estudar. Para respondê-los, o estudante utiliza uma escala de cinco pontos, variando de 1 = Completamente falso a $\mathbf{5}$ = Completamente verdadeiro. Uma análise fatorial confirmatória permitiu observar a adequação de sua estrutura unifatorial ao contexto paraibano: $\chi^{2}(9)=$ $22,10, p<0,009, \chi^{2} / \mathrm{gl}=2,46, \mathrm{GFI}=0,97, A G F I=0,93, \mathrm{CFI}=$ 0,95 e RMSEA $=0,08(I C 90 \%=0,036-0,118)$, que apresentou alfa de Cronbach de 0,74 (Fonsêca e cols., 2013).

O Questionário de Percepção dos Pais é uma medida originalmente construída por Pasquali e Araújo (1986) e se compõe de 20 itens igualmente distribuídos para representar as dimensões responsividade (e.g.Consola-me quando estou com medo; Procura me animar quando estou triste) e exigência (e. g., Acha que deve me castigar para me corrigir e melhorar; Acredita que todos os meus comportamentos maus devem ser castigados de alguma forma). Há duas versões, uma para o pai e outra para a mãe. Para cada item da escala, o participante deve indicar em que medida o comportamento ou a atitude descrita é aplicável a seus pais ou os descreve. Para isso se utiliza uma escala de respostas de cinco pontos, variando de $\mathbf{0}=$ Nada aplicável a $4=$ Totalmente aplicável. Pasquali e cols. (2012) encontraram evidências de que o instrumento é bifatorial. A versão materna explicou $37,9 \%$ da variância total e os coeficientes de consistência interna (alfas de Cronbach) foram 0,84 e 0,73 para responsividade e exigência, respectivamente. A versão paterna explicou $41,4 \%$ da variância total e os coeficientes de consistência interna (alfas de Cronbach) foram 0,86 e 0,85 para responsividade e exigência, respectivamente.

Informações Demográficas. Os participantes também responderam quatro perguntas de natureza demográfica, a saber: idade, sexo, escolaridade e tipo de escola (pública vs. privada).

\section{Procedimento}

\section{Coleta de dados}

Após a autorização dos diretores das escolas e o consentimento dos responsáveis pelos participantes, agen- daram-se datas para a aplicação dos instrumentos. Todos os estudantes responderam os questionários individualmente, porém em ambiente coletivo de sala de aula. Dois bolsistas treinados foram responsáveis por coletar os dados em um único encontro. Na ocasião, os estudantes foram orientados a preencher o questionário escolhendo a alternativa que melhor representasse sua percepção acerca dos seus hábitos de estudo e do estilo parental adotado pelos pais (pai e mãe). Os aplicadores ficaram em sala para dirimir dúvidas quanto à forma de responder o instrumento, mas nunca quanto ao conteúdo dos itens. O tempo médio para concluir a participação foi de aproximadamente 20 minutos. Todos os participantes moravam com ambos os genitores, pois aqueles que não conviviam com algum deles foram excluídos do estudo.

\section{Análise dos dados}

Os dados foram tabulados e analisados por meio do PASW (Predictive Analytics Software; versão 20). Inicialmente, buscou-se calcular as estatísticas descritivas (medidas de tendência central e dispersão) para caracterização do grupo amostral; em seguida foi realizada a estatística bivariada (correlação de Pearson) para verificar como se associavam as variáveis estudadas (as dimensões dos estilos parentais e os hábitos de estudo) e as multivariadas (MANOVA), para ver o efeito das variáveis sociodemográficas na pontuação da Escala de Hábitos de Estudo e no Questionário de Percepção dos Pais.

\section{Considerações éticas}

O presente estudo foi avaliado e aprovado pelo Comitê de Ética em Pesquisa com Seres Humanos do Hospital Universitário Lauro Wanderley (CEP/HULM), sob o Protocolo $n^{\circ}$ 140/11. Após a explicação dos procedimentos da pesquisa para os diretores das escolas e pais, foi solicitada a permissão para a participação dos estudantes na pesquisa, a qual foi concedida com a assinatura do Termo de Consentimento Informado pelos pais ou responsáveis, conforme recomenda a Resolução 196/2013 do Conselho Nacional de Saúde. Aos participantes foi garantida a confidencialidade dos resultados e informado o caráter voluntário da pesquisa, dando-lhes o direito de desistir do estudo a qualquer momento, sem incorrer em qualquer penalidade.

\section{Resultados}

Os resultados serão apresentados em subtópicos, organizados de acordo com o tipo de análise empregado para tratamento dos dados. Por isso, inicialmente apresentar-se-á a correlação entre as dimensões dos estilos parentais e os hábitos de estudo.

Correlação entre as dimensões dos estilos parentais e os hábitos de estudo

Realizando a correlação entre as dimensões (responsividade e exigência) dos estilos parentais e os hábitos de 
estudo, pôde-se verificar uma correlação entre as dimensões responsividade materna $(r=0,19 ; p<0,01)$ e responsividade paterna $(r=0,16 ; p<0,01)$. Não se observou correlação das dimensões exigência materna $(r=0,03)$ e exigência paterna $(r=0,06)$ com os hábitos de estudo (ver Tabela 1$)$.

Tabela 1. Correlação entre as Dimensões dos Estilos Parentais e os Hábitos de Estudo

\begin{tabular}{cc}
$\begin{array}{c}\text { Dimensões dos Estilos } \\
\text { Parentais }\end{array}$ & Hábitos de Estudo \\
\cline { 2 - 2 } Responsividade Materna & $0,19^{* *}$ \\
Responsividade Paterna & $0,16^{* *}$ \\
Exigência Materna & 0,03 \\
Exigência Paterna & 0,06
\end{tabular}

Notas: ${ }^{* *} p<0,01$ (teste de significância bicaudal, com eliminação dos casos em branco - missing - através do método pairwise).

\section{Análise multivariada}

Para verificar as diferenças das dimensões (responsividade e exigência) dos estilos parentais e os hábitos de estudo em função das variáveis sociodemográficas, efetuou-se uma MANOVA considerando as três variáveis intersujeito: sexo (masculino e feminino), tipo de escola (pública vs. privada) e série $\left(7^{\circ}\right.$ e $9^{\circ}$ anos do Ensino Fundamental e $2^{\circ}$ ano do Ensino Médio). Neste sentido, realizou-se uma MANOVA considerando-se como variáveis de critério as dimensões (responsividade e exigência) estilos parentais e hábitos de estudo, e as variáveis demográficas como antecedentes.

As três variáveis sociodemográficas apresentaram os efeitos principais: sexo [Lambda de Wilks $=0,96, F(5,495)$ $=4,54, p<0,001$, tamanho do efeito $=0,04]$, tipo de escola [Lambda de Wilks $=0,94, F(5,495)=5,95, p<0,001$, tamanho do efeito $=0,05]$ e escolaridade [Lambda de Wilks $=$ $0,86, F(10,990)=7,71, p=0,001$, tamanho do efeito $=0,07]$.

Com relação ao sexo, os testes univariados indicaram haver diferença em relação aos hábitos de estudo $[F(1,499)$ $\left.=6,65, p<0,01, \eta^{2} 0,01\right]$, a dimensão responsividade paterna $\left[F(1,499)=8,19, p<0,01, \eta^{2} 0,02\right]$ e materna $[F(1,499)=9,06$, $\left.p<0,01, \eta^{2} 0,02\right]$ e a dimensão exigência paterna $[F(1,499)=$ $\left.11,55, p<0,001, \eta^{2} 0,02\right]$. Especificamente, observou-se, no teste post hoc de Bonferroni, que os participantes do sexo masculino obtiveram médias maiores nos hábitos de estudo ( $m=17)$ do que os do feminino $(m=15,91)$; Na dimensão responsividade paterna, os participantes do sexo masculino obtiveram médias superiores $(m=4,55)$ às do sexo feminino ( $m=4,15$ ); e na responsividade materna verificou-se que as médias dos participantes do sexo masculino foram mais elevadas $(m=5,18)$ do que as do sexo feminino $(m=4,81)$; por fim, na dimensão autoridade paterna, encontrou-se, por meio do teste post hoc de Bonferroni, que os participantes do sexo masculino obtiveram médias maiores $(m=4,19)$ que as do sexo feminino $(m=3,80)$

Com relação ao tipo de escola, os testes univariados indicaram haver diferença em relação aos hábitos de estudo $\left[F(1,499)=10,55, p<0,001, \eta^{2} 0,02\right]$, nas dimensões afetividade paterna $\left[F(1,499)=10,90, p<0,01, \eta^{2} 0,02\right] \mathrm{e}$ afetividade materna $\left[F(1,499)=5,91, p<0,01, \eta^{2} 0,01\right]$. De forma específica, ao se compararem os grupos (teste post hoc de Bonferroni), observou-se que os participantes da escola pública pontuaram mais alto nos hábitos de estudo $(m=17,15)$ do que os da escola particular $(m=15,76)$. Na dimensão responsividade paterna, os participantes da escola particular $(m=4,58)$ obtiveram médias maiores do que as dos da escola pública $(m=4,12)$; e na dimensão responsividade materna, os estudantes da escola particular $(m=5,14)$ obtiveram médias superiores às dos da escola pública $(m=4,85)$.

No tocante à escolaridade, os testes univariados indicaram haver diferença em relação aos hábitos de estudo $\left[F(2,499)=22,61, p<0,001, \eta^{2} 0,08\right]$ na dimensão responsividade paterna $\left[F(2,499)=6,92, p<0,001, \eta^{2} 0,03\right]$ e responsividade materna $\left[F(2,499)=5,86, p<0,01, \eta^{2} 0,02\right]$, e nas dimensões exigência paterna $\left[F(2,499)=9,20, p<0,001, \eta^{2}\right.$ $0,04]$ e exigência materna $\left[F(2,499)=12,59, p<0,001, \eta^{2}\right.$ $0,05]$. De modo específico, constatou-se, através do teste post hoc de Bonferroni, que as médias dos hábitos de estudo dos participantes do sétimo ano são maiores $(m=18,27)$ do que os do nono ano $(m=16,33)$, que por sua vez são superiores às dos estudantes do $2^{\circ}$ ano do Ensino Médio ( $m=14,77)$; Com relação à dimensão responsividade paterna, a comparação dos grupos revelou que os estudantes do sétimo ano obtiveram médias maiores $(m=4,65)$ às dos estudantes do nono ano $(m=4,37)$ e do $2^{\circ}$ ano do Ensino Médio ( $m=4,02)$; e em responsividade materna, verificou-se que os participantes do sétimo ano obtiveram médias mais elevadas $(m=5,20)$ que as dos estudantes do nono ano $(m=$ $5,08)$ e do $2^{\circ}$ ano do Ensino Médio $(m=4,70)$; Na dimensão exigência paterna constatou-se que os participantes do sétimo ano obtiveram médias superiores $(m=4,26)$ às dos participantes do nono ano $(m=4,06)$ e do $2^{\circ}$ ano do Ensino Médio ( $m=3,68$ ); resultado semelhante foi verificado com exigência materna, em que se constatou que os participantes do sétimo ano obtiveram médias maiores $(m=4,36)$ do que as dos do nono ano $(m=4,35)$ e do $2^{\circ}$ ano do Ensino Médio $(m=3,83)$.

Os efeitos da interação foram observados entre o tipo de escola e a escolaridade [Lambda de Wilks $=0,95$, $F(10,990)=2,57, p=0,05$, tamanho do efeito $=0,02]$, sendo as diferenças observadas em relação aos hábitos de estudo $\left[F(2,100)=4,50, p<0,05, \eta^{2} 0,02\right]$ e na dimensão responsividade paterna $\left[F(2,6,86)=2,91, p<0,05, \eta^{2} 0,01\right]$. Especificamente, constatou-se que as médias em hábitos de estudo dos estudantes da escola particular do sétimo ano ( $m=18,36)$ eram superiores às dos estudantes da escola pública $(m=18,18)$, ao contrário do que se evidenciou com relação aos participantes do nono ano da escola pública, os apresentaram médias maiores $(m=17,8)$ do que as dos da escola particular $(m=18,85)$, fato que se repetiu com os do 
$2^{\circ}$ ano do Ensino Médio de escola pública, os quais obtiveram médias maiores $(m=15,46)$ do que as dos estudantes da escola particular $(m=14)$. Quanto à dimensão responsividade paterna, verificou-se que os estudantes da escola particular apresentaram médias elevadas no sétimo ano $(m$ $=4,68)$, nono ano $(m=4,81)$ e $2^{\circ}$ ano do Ensino Médio $(m=$ 4,24 ) do que as dos estudantes do sétimo da escola pública ( $m=4,62)$ e do nono ano $(m=3,93)$ e do $2^{\circ}$ ano do Ensino Médio $(m=3,81)$.

\section{Discussão}

O presente estudo teve por objetivo correlacionar as dimensões dos estilos parentais (responsividade e exigência) com os hábitos de estudo dos adolescentes. Especificamente, pretendeu-se verificar a interferência das variáveis sociodemográficas (sexo, escolaridade e tipo de escola) nos hábitos de estudo e nas dimensões dos estilos parentais (responsividade e exigência). Para alcançar tais objetivos, foram calculadas estatísticas descritivas para caracterização do grupo amostral e as correlações de Pearson ( $r$ ) para verificar como se associavam os construtos estudados (Dimensões dos Estilos Parentais e Hábitos de Estudo) e uma MANOVA, para ver o efeito das variáveis sociodemográficas na pontuação das escalas.

Pelos resultados encontrados, pode-se considerar que há influência da dimensão responsividade do estilo parental na construção de hábitos de estudo dos adolescentes, o que vem comprovar a importância de tal variável no processo educacional dos jovens. A propósito, pode-se dizer que os pais e mães que adotam os estilos parentais autoritativo e permissivo - os quais apresentam um nível alto de responsividade - possivelmente apresentam atitudes de aceitação e compreensão e mantêm uma boa comunicação com os filhos, fatores que ajudam os adolescentes na construção da autonomia, confiança e regulação do comportamento (Justo, \& Lipp, 2010; Weber e cols., 2006).

De modo contrário, a dimensão exigência dos estilos parentais não demonstrou correlação com os hábitos de estudo; todavia, os resultados devem ser ponderados uma vez que a correlação evidenciada com a dimensão responsividade não foi expressiva, mas uma correlação baixa; mas isto é importante indicador de que atitudes mais afetivas dos genitores comntribuem para que os filhos venham a desenvolver hábitos de estudo, quiçá pela construção de uma via de comunicação entre os pais e os adolescentes, permitindo que estes expressem suas necessidades e dificuldades e, conjuntamente, encontrem soluções para as questões enfrentadas pelos jovens (Pacheco e cols, 2008; Rinhel-Silva e cols., 2012). Tal resultado vem corroborar os de outras pesquisas (Pacheco e cols., 1999; Salvo, 2010), segundo as quais a dimensão exigência está relacionada a pessoas preocupadas e inseguras quanto aos seus próprios desempenhos.

Quanto às variáveis sociodemográficas, observou-se que o sexo do estudante, o tipo de escola (pública e particular) e o nível de escolaridade $\left(7^{\circ}\right.$ ano e $9^{\circ}$ ano do En- sino Fundamental e $2^{\circ}$ ano do Ensino Médio) influenciam na pontuação na escala dos hábitos de estudo e no questionário de percepção dos pais.

Quanto ao sexo dos participantes, os resultados evidenciaram que os meninos apresentaram mais hábitos de estudo do que as meninas. Este resultado diverge dos achados da literatura (Ramalho, 2001), os quais apontam as meninas como estudantes mais organizadas, motivadas e realizadoras de atividades durante as aulas do que os meninos. Pode-se explicar tal resultado como um fato específico da amostra estudada, sendo necessários novos estudos acerca do tema.

De igual modo, também foi encontrado que os meninos perceberam os pais e as mães com maior nível de responsividade e os pais com elevada exigência. Esses resultados se assemelham aos encontrados por Silva e cols. (2012), os quais, ao analisarem os dados em relação à exigência e responsividade por sexo numa amostra composta por 62 adolescentes com idades entre 12 e 17 anos, encontraram escores mais altos para os meninos, nas duas dimensões. As autoras acreditam que este resultado possa estar relacionado ao fato de os meninos estarem envolvidos em maior contexto de vulnerabilidade social, e em decorrência disso, é possível que os pais estejam dialogando mais, fazendo mais exigências e impondo regras de obediência e limites aos meninos, como forma de evitar que estes se envolvam em atos de violência, consumo de álcool e drogas.

Analisando o tipo de escola, averiguou-se que os participantes da escola pública demonstraram um maior nível de hábitos de estudo, o que pode estar relacionado ao fato de os estudantes encontrarem no estudo um meio de crescimento profissional, enquanto os participantes da escola particular podem não entender o estudo como necessário para suas vidas e e assim não desenvolverem esta prática. Este fato pode ser constatado no estudo de Skovsmose, Scandiuzzi, Valero e Alrø (2012), no qual os estudantes de escolas públicas, provenientes de um contexto social desfavorecido (favelas), indicaram ver nos estudos a possibilidade de mudança de vida no futuro. Por outro lado, estudos recentes (Brandão, Canedo, \& Xavier, 2012; Otaviano, Alencar, \& Fukuda, 2012) mostram que os estudantes de escola particular apresentam mais prática de hábitos de estudo, uma vez que têm melhores condições estruturais, familiares e materiais.

Já com relação à escolaridade, pôde-se observar que os estudantes do sétimo ano do ensino fundamental apresentaram hábitos de estudo superiores aos dos outros anos escolares (sétimo ano do Ensino Fundamental e $2^{\circ}$ ano do Ensino Médio). Um aspecto a ser analisado é a idade dos estudantes, afinal, os participantes com idades menores (sétimo ano) parecem obedecer mais aos pais e atender às orientações e valores parentais, o que não acontece com os estudantes do oitavo ano do Ensino Fundamental e do $2^{\circ}$ ano do Ensino Médio, os quais são adolescentes e devem se perceber como autônomos e independentes quanto aos estudos.

Do mesmo modo, os estudantes do sétimo ano do Ensino Fundamental perceberam os pais e as mães com níveis altos de responsividade e exigência. É plausível que se 
tenha encontrado esse resultado, uma vez que a afetividade e autoridade estão mais presentes nesta idade da vida do filho, que requer mais atenção, companheirismo e monitoramento do comportamento. As estratégias educativas utilizadas pelos pais tendem a se modificar à medida que o filho vai se desenvolvendo, e conforme os filhos crescem os pais tendem a exercer menor controle e supervisão, conforme se observou entre os estudantes do Ensino Médio. Nesta fase, os pais tendem a estimular a autonomia e a independência, além de utilizarem mais explicações verbais, restrição de privilégios e estratégias punitivas (Reppold e cols., 2002).

\section{Conclusão}

Diante do exposto, pode-se concluir que a relação que os pais estabelecem com os filhos influencia, de forma positiva ou negativa, a construção de hábitos de estudos. $A$ dimensão responsividade dos estilos parentais está relacionada aos estilos autoritativo e permissivo, pois ambos apresentam um nível alto de envolvimento e afetividade dos pais e mães para com os filhos, aspecto positivo na construção de um relacionamento baseado na reflexão da organização e sistematização nos estudos. A dimensão exigência está presente em um nível elevado nos estilos autoritário e autoritativo. De acordo com Maccoby e Martin (1983), quando há equilíbrio entre a responsividade e a exigência, evidencia-se o estilo autoritativo, o qual é apontado pela literatura como o mais benéfico para a educação dos filhos. Por outro lado, quando está presente apenas a dimensão exigência, próprio do estilo autoritário, constatam-se problemas de comunicação, insegurança, depressão e isolamento nas crianças.

De modo geral, os resultados apontaram que os estudantes perceberam seus pais como mais responsivos, especialmente os meninos, e essa dimensão sofria influência das características sociodemográficas da amostra, a saber: a escolaridade, o sexo e o tipo de escola.

Assim, parece que uma combinação, ainda que em graus variados, de exigência e responsividade, é necessária para o desenvolvimento dos hábitos de estudo. Em contraste, o distanciamento parental, típico do estilo negligente, parece não favorecer o desenvolvimento dos hábitos de estudo. Esse resultado confere com o já descrito em outros estudos, nos quais o estilo negligente apresenta os piores resultados enquanto indicadores de desenvolvimento psicossocial (Camacho, \& Matos, 2007; Pacheco e cols., 2008; Rinhel-Silva e cols., 2012; Salvo, 2010). Deste modo, constata-se que é relevante a ação dos pais no sentido de estabelecer ambientes físicos e psíquicos adequados para a promoção dos hábitos de estudo dos seus filhos, estando disponível diante das suas necessidades acadêmicas e pessoais, estabelecendo modelos estruturados para a distribuição do tempo dedicado aos estudos e proporcionando espaços e materiais para a realização das atividades escolares.

Embora este estudo tenha alcançado o objetivo esperado, cumpre referir suas limitações, entre elas a amostra e os locais de aplicação. Primeiramente, não se contou neste estudo com uma amostra numericamente representativa da população de estudantes paraibanos, visto que o estudo foi desenvolvido em apenas duas escolas, uma pública e uma particular, da cidade de João Pessoa. Assim, considera-se de grande importância levar a cabo estudos com amostras mais abrangentes, para que os dados sejam mais bem apurados e estejam condizentes com a realidade paraibana. Outra limitação diz respeito ao tipo de instrumento utilizado, o autorrelato, em que os próprios participantes respondiam o questionário. Nesse caso, o uso dessa medida está suscetível à influência da desejabilidade social, o que tende a enviesar e mascarar os resultados.

É importante destacar que, apesar das limitações, o estudo pode oferecer indícios da importância da relação parental na formação acadêmica dos filhos, particularmente na construção de hábitos de estudos. Ademais, apontou a relevância das variáveis sociodemográficas para a compreensão das variáveis hábitos de estudo e dimensões do estilo parental, informação que vem auxiliar educadores, psicólogos e pais na realização de propostas de intervenção.

Para pesquisas futuras, sugere-se a realização de estudos que relacionem os hábitos de estudo a outras variáveis, como, por exemplo, os valores humanos, a personalidade, a motivação e os estilos de ensino dos professores.

\section{Referências}

Benson, C. S.; Buckley, S.; Medrich, E. (1980). Families as educators: Time use contributions to school achievement. Em J. Guthrie (Org.). School finance policy in the 1980's: A decade of conflict, Cambridge: Ballinger.

Boruchovitch, E. (1999). Estratégias de aprendizagem e desempenho escolar: considerações para a prática educacional. Psicologia: Reflexão e Crítica, 12(2), 361-376.

Brandão, Z.; Canedo, M. L., \& Xavier, A. (2012). Construção solidária do habitus escolar: resultados de uma investigação nos setores público e privado. Revista Brasileira de Educação. 17(49), 193218.

Instituto Nacional de Estudos e Pesquisas Educacionais Anísio Teixeira (INEP). (2009). Sinopse estatística da educação básica. Recuperado: 17 dez. 2012. Disponível: http://www.inep. gov.br/basica/censo/Escolar/Sinopse/sinopse.asp.

Camacho, I., \& Matos, M.G. (2007). Práticas parentais educativas, fobia social e rendimento académico em adolescentes. Revista Brasileira de Terapias Cognitivas, 3, 1-15.

Carita, A., Silva, A.C., Monteiro, A.F, \& Diniz, T.P. (1997). Como ensinar a estudar. Lisboa: Edtorial Presença.

Cia, F., Pereira, C. S., Del Prette, Z. A. P., \& Del Prette, A. (2006). Habilidades sociais parentais e o relacionamento entre pais e filho. Psicologia em Estudo, 11(1), 73-81. 
Fonsêca, P. N., Sousa, D. M. F., Gouveia, Souza Filho, J. F., \& Gouveia, V. V. (2013). Escala de Hábitos de Estudo: Evidências de validade de Construto. Revista Avaliação Psicológica, 12 (1), 71-79.

Granetto, W. E. (2008). Práticas Educativas Parentais em Dependentes Químicos. Dissertação de Mestrado, Instituto de Ciências da Vida, Pontifícia Universidade Católica de Campinas (PUCCAMP), Campinas, São Paulo.

Hodapp, V., \& Heuneberger, A. (1983). Test anxiety, study habits, and academic performance. Em H. M. Van der Ploeg, R. Schwarzer, \& C. D. Spielberger (Orgs.), Advances in test anxiety research (Vol. 3, pp. 119-127). Lisse, The Netherlands: Swets \& Zeitlinger.

Justo, A. P., \& Lipp, M. E. N. (2010). A influência do estilo parental no stress do adolescente. Boletim Academia Paulista de Psicologia, 30(79), 363-378.

Lozano, A. B.,Mascarenhas, S. A. N., \& Blanco, J. C. B. (2004). Variáveis familiares e escolares determinantes do rendimento acadêmico no ensino médio no Estado de Rondônia, Amazônia, Brasil. Revista Linhas (UDESC), 5(2), 1-31.

Maccoby, E., \& Martin, J. (1983). Socialization in the context of the family: Parent-child interaction. Em E. M. Hetherington (Org.), Handbook of child psychology (Vol. 4, pp. 1-101). New York: Wiley.

Maximiano, A. C. A. (2008). Teoria geral da administração: da revolução urbana à revolução digital. São Paulo: Atlas.

Otaviano, A. B. N., Alencar, E. M. L. S., \& Fukuda, C. C. (2012). Estímulo à criatividade por professores de Matemática e motivação do aluno. Revista Semestral da Associação Brasileira de Psicologia Escolar e Educacional, 16(1), 61-69.

Pacheco, J. T. B., Silveira, L. M. O. B., \& Schneider, A. M. A.(2008). Estilos e práticas educativas parentais: análise da relação desses construtos sob a perspectiva dos adolescentes. Psico, 39(1), 6673.

Pacheco, J.T.B, Teixeira, M.A.P, \& Gomes, W.B. (1999). Estilos parentais e desenvolvimento de habilidades sociais na adolescência. Psicologia: Teoria e Pesquisa, 15(2), 117-126.

Pasquali, L., \& Araújo, J. M. A. (1986). Questionário de Percepção dos Pais - Q.P.P. Psicologia: Teoria e Pesquisa, 2 (1), 56-72.

Pasquali, L., Gouveia, V. V., Santos, W. S., Fonseca, P. N., \& Lima, T. J. S. (2012). Questionário de percepção dos pais: Evidências de uma medida de estilos parentais. Paidéia, 22, 155-164.

Regra, J.A.G. (2004). Aprender a estudar. Em M.M.C. Hübner, \& M. Marinotti (Orgs.). Análise do Comportamento para a Educação: contribuições recentes (pp. 225-242). Santo André: ESETec Editores Associados.
Ramalho, J. (2001). Os hábitos de estudo em estudantes do $3^{\circ}$ ciclo do ensino básico e do $1^{\circ}$ ano do ensino secundário. Monografia de Graduação, Universidade Fernando Pessoa, Porto, Portugal.

Reppold, C. T., Pacheco, J., Bardagi, M., \& Hutz, C. S. (2002). Prevenção de problemas de comportamento e desenvolvimento de competências psicossociais em crianças e adolescentes: Uma análise das práticas educativas e dos estilos parentais. Em C. S. Hutz (Org.), Situações de risco e vulnerabilidade na infância e adolescência: Aspectos teóricos e estratégias de intervenção (pp. 7-51). São Paulo: Casa do Psicólogo.

Rinhel-Silva, C. M., Constantino, E. P., \& Rondini, C. A. (2012). Família, adolescência e estilos parentais. Estudos de Psicologia. 29(2), 221-230.

Rosário, P., Nunes, T., Magalhães, C., Rodrigues, A., Pinto, R., \& Ferreira, P. (2010). Processos de auto-regulação da aprendizagem em alunos com insucesso no $1 .^{\circ}$ ano de Universidade. Psicologia Escolar e Educacional, 14(2), 349-358.

Salvo, C. G. (2010). Práticas educativas parentais e comportamentos de proteção e Risco à saúde em adolescentes. Tese de Doutorado, Instituto de Psicologia, Universidade de São Paulo, São Paulo.

Santos, P. L., \& Graminha, S. S. V. (2006). Problemas emocionais e comportamentais associados ao baixo rendimento acadêmico. Psicologia em Estudo, 11(1), 101-109.

Skovsmose, O., Scandiuzzi, P. P., Valero, P., \& Alrø, H. (2012). A Aprendizagem Matemática em uma Posição de Fronteira: foregrounds e intencionalidade de estudantes de uma favela brasileira. Bolema, 26(42), 231-260.

Watanabe, O. M., Cassetari, L., Santos, M. L. M., Lombard-Platet, V. L. V., \& Di Domenico, V. G. C. (2001). Um levantamento dos hábitos de estudo dos alunos do curso de psicologia do centro universitário FMU (Faculdades Metropolitanas Unidas). Psikhê, 6, 60-71.

Watkins, M. W., \& Coffey, D. Y. (2004). Reading motivation: Multidimensional and indeterminate. Journal of Education Psychology, 96, 110-118.

Weber, L. N. D., Brandenburg, O. J., \& Viezzer, A.P. (2003). A relação entre o estilo parental e o otimismo da criança. Revista Psico-USF, 8(1), 71-79.

Weber, L. N. D., Selig, G. A., Bernardi, M. G. \& Salvador, A. P. V. (2006). Continuidade dos estilos parentais através das geraçõestransmissão intergeracionais de estilos parentais. Paidéia, 16 (35), 407-414 
Recebido em: 02/02/2013

Reformulado em: 13/01/2014

Aprovado em: 13/02/2014

\section{Sobre as autoras}

Patrícia Nunes da Fonsêca (patynfonseca@hotmail.com)

Profa. Dra. da Pós-graduação em Psicologia Social, UFPB.

Patrícia Oliveira de Andrade (patriciaandrad.cel@gmail.com)

Graduada em Psicopedagogia, Universidade Federal da Paraíba - UFPB.

Jérssia Laís Fonsêca dos Santos (jerssynhalais@hotmail.com)

Graduada em Psicopedagogia, Universidade Federal da Paraíba - UFPB.

Jéssica Emmily Monteiro Cunha (jessicaemmily2@gmail.com)

Graduada em Psicopedagogia, Universidade Federal da Paraíba - UFPB.

Juliana Henrique de Assis Albuquerque (juhalbuquerque_@hotmail.com)

Graduanda em Psicopedagogia, Universidade Federal da Paraíba - UFPB.

O presente artigo contou com apoio do CNPq por meio de bolsa de Iniciação Científica concedida ao segundo autor. Os autores agradecem a esta instituição. 